\title{
Safeguards Approaches for Black Box Processes or Facilities
}

\author{
H Diaz Marcano \\ ET Gitau \\ E Miller \\ J Hockert \\ J Wylie
}

September 2013

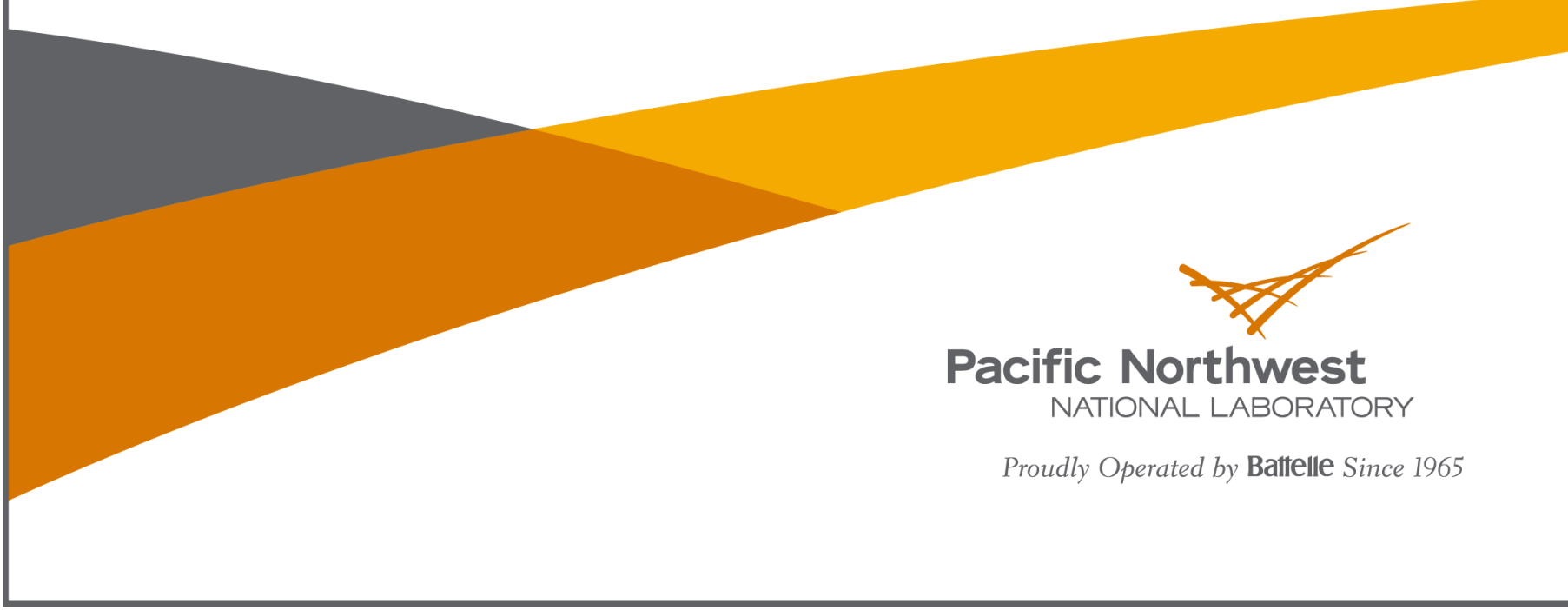




\title{
DISCLAIMER
}

This report was prepared as an account of work sponsored by an agency of the United States Government. Neither the United States Government nor any agency thereof, nor Battelle Memorial Institute, nor any of their employees, makes any warranty, express or implied, or assumes any legal liability or responsibility for the accuracy, completeness, or usefulness of any information, apparatus, product, or process disclosed, or represents that its use would not infringe privately owned rights. Reference herein to any specific commercial product, process, or service by trade name, trademark, manufacturer, or otherwise does not necessarily constitute or imply its endorsement, recommendation, or favoring by the United States Government or any agency thereof, or Battelle Memorial Institute. The views and opinions of authors expressed herein do not necessarily state or reflect those of the United States Government or any agency thereof.

\author{
PACIFIC NORTHWEST NATIONAL LABORATORY \\ operated by \\ BATTELLE \\ for the \\ UNITED STATES DEPARTMENT OF ENERGY \\ under Contract DE-AC05-76RL01830
}

Printed in the United States of America
Available to DOE and DOE contractors from the Office of Scientific and Technical Information, P.O. Box 62, Oak Ridge, TN 37831-0062; ph: (865) 576-8401 fax: $(865) 576-5728$
email: reports $a$ adonis.osti.gov
Available to the public from the National Technical Information Service 5301 Shawnee Rd., Alexandria, VA 22312 ph: (800) 553-NTIS (6847) email: orders@ntis.gov <http://www.ntis.gov/about/form.aspx> Online ordering: http://www.ntis.gov




\title{
Safeguards Approaches for Black Box Processes or Facilities
}

\author{
H Diaz Marcano $^{1} \quad$ E Miller $^{2}$ \\ ET Gitau J Wylie ${ }^{2}$ \\ J Hockert $^{2}$
}

September 2013

Prepared for

the U.S. Department of Energy

under Contract DE-AC05-76RL01830

Pacific Northwest National Laboratory

Richland, Washington 99352

\footnotetext{
${ }^{1}$ Savannah River National Laboratory, Aiken, South Carolina

${ }^{2}$ XE Corporation, Idaho Falls, Idaho
} 


\section{Executive Summary}

As part of the Next Generation Safeguards Initiative, the National Nuclear Security Administration is exploring and developing innovative safeguards approaches at nuclear facilities to increase the effectiveness of International Atomic Energy Agency (IAEA) safeguards. The body of research described in this report has particular relevance to facilities where the use of proprietary or classified technologies, or in some cases, radiation protection requirements, precludes IAEA access. In some cases, a State or operator may limit IAEA access to specific processes or portions of a facility; in other cases, the IAEA may be prohibited access to the entire facility.

The objective of this study is to determine whether a safeguards approach can be developed for such "black box" processes or facilities. The determination of whether a black box process or facility is safeguardable is dependent upon the details of the process type, design, and layout; the specific limitations on inspector access; and the restrictions placed upon the design information that can be provided to the IAEA. In short, this analysis identified the necessary conditions for safeguardability of black box processes and facilities.

The following conditions must be met in order for the IAEA to draw a valid conclusion that nuclear material has not been diverted from the black box process:

- The black box process is located within an area of the facility that is surrounded by a physical barrier and has been defined as a material balance area (MBA). The flow key measurement points for the black box process MBA are located outside of the physical barrier and are accessible for IAEA inspection.

- The nuclear material accounting and control (NMAC) system is sufficiently robust to detect the loss or diversion of the "test statistic" from the black box process MBA in a timely fashion.

- The design and layout of the black box process or area permits inspector verification of the measured values of the material balance components for the black box process MBA, with the exception of the quantity of nuclear material in inventory identified as unverifiable in the design information submittal.

- The design and layout of the black box process or area permits the installation and operation of containment and surveillance measures that provide assurance that all transfers of nuclear material are reflected in the NMAC system. Such measures should ensure that sensitive or radioactive equipment transferred into and out of the black box process MBA cannot be used to conceal transfers of undeclared nuclear material.

- The design and layout of the black box process or area permits design verification by inspector examination or other means to ensure that no undeclared penetrations have been made to the physical barrier surrounding the black box area.

The study also identified the following conditions that must also be met in order for the IAEA to draw a valid conclusion that the process has not been used for an undeclared purpose:

- The design and layout of the black box process or area permits inspector design verification to ensure that the as-built facility has not changed in ways that degrade the effectiveness of the containment or surveillance measures. 
- The design information provided by the State is sufficient for the IAEA to identify misuse paths (scenarios) and indicators, and to develop a safeguards approach that detects their use or closes the misuse paths.

Although facility designers can use the aforementioned conditions to consciously design black box facilities or processes for safeguardability, these requirements are not always sufficient. Verification capabilities of the IAEA at black box facilities can best be enhanced with the development of

- advanced detection materials that will push advancement in the non-destructive analysis and destructive analysis systems available to perform nuclear material measurement in support of NMAC

- containment and surveillance measures designed for use within black boxes where the IAEA has limited access, and for use at the exterior of the black box boundary to verify container integrity and contents

- systems capable of performing unattended, remote design information verification within black box areas and technologies capable of detecting undeclared, or hidden penetrations from outside the black box

- advanced systems capable of performing environmental sampling and analysis on-site

- real-time, or near-real-time, process monitoring systems capable of operating in an unattended manner and remotely or in sensitive process areas.

Ultimately, black box facilities, or entire facilities that are inaccessible to IAEA inspectors because of information protection or radiation protection purposes, pose the greatest challenge to IAEA effectiveness. In this case, the powers granted to the IAEA in a State with an Additional Protocol in force will be essential to the ability of the IAEA to verify that no diversion has occurred and that no undeclared material or activities have been pursued by the State at the black box facility. In addition, the development of safeguards design guidance and tools for determining safeguardability for use by facility designers, operators, and States, independent of engagement with the IAEA, will be crucial to reduce the need for black boxes that encompass entire facilities. With these types of tools, the safeguardability evaluation of black box processes can be initiated early in the design process such that design or process modifications can be completed to ensure that the as-built facility is safeguardable. 


\section{Acronyms and Abbreviations}

3DLR

AEM

AP

CA

CEMO

$\mathrm{C} / \mathrm{S}$

CLYC

DA

DIE

DIV

EOSS

ESI-MS

$\mathrm{F} \& \mathrm{~W}$

GCEP

HEU

IAEA

INFCIRC

KMPs

LAARS

MBA

MBP

MTSWU

MUF

NDA

NGSI

NMAC

NNSA

PIV

RRP

SMMS

SRA

SSAC

SWU

$\mathrm{U}$

${ }^{235} \mathrm{U}$

$\mathrm{UF}_{6}$
3D Laser Range Finder

advanced enrichment monitor

Additional Protocol

complementary access

continuous enrichment monitor

containment and surveillance

$\mathrm{Cs}_{2} \mathrm{LiYCl}_{6}: \mathrm{Ce}$

destructive assay

design information examination

design information verification

electronic optical sealing system

electrospray ionization mass spectroscopy

feed and withdrawal

gas centrifuge enrichment plant

highly enriched uranium

International Atomic Energy Agency

International Atomic Energy Agency Information Circular

key measurement points

laser ablation, absorbance ratio spectroscopy

material balance area

material balance period

metric tonnes - separative work units

material unaccounted for

non-destructive assay

Next Generation Safeguards Initiative

nuclear material accounting and control

National Nuclear Security Administration

physical inventory verification

Rokkasho Reprocessing Plant

solution measurement and monitoring system

safeguards regulatory authority

States' system of accounting for and control of nuclear material

Separative Work Unit

uranium

uranium-235

uranium hexafluoride 


\section{Contents}

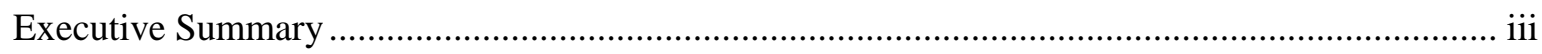

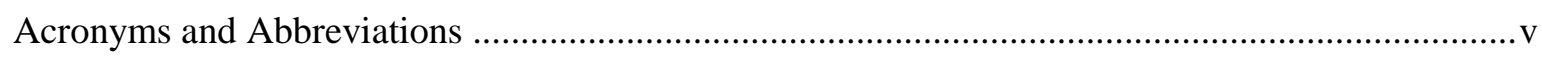

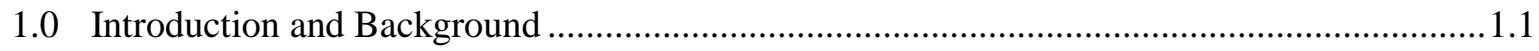

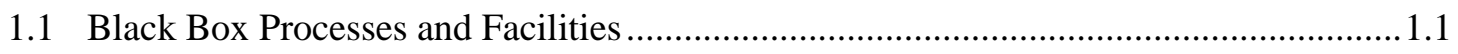

2.0 Effects of Black Box Constraints on Safeguards Measures .................................................2.1

2.1 Safeguards Measures for Detection of Diversion......................................................... 2.1

2.1.1 Nuclear Material Accounting and Control .....................................................2.1

2.1.2 IAEA Inventory Verification and Inspection ...............................................2.2

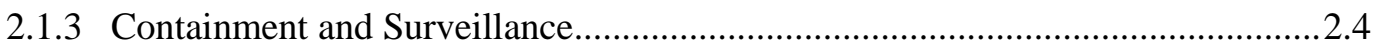

2.1.4 Design Information Process (Examination and Verification) .............................2.5

2.1.5 Necessary Conditions for Safeguardability - Diversion Detection .......................2.8

2.2 Safeguards Measures for Detection of Facility Misuse ..............................................2.9

2.2.1 Design Information Process (Examination and Verification) .............................2.9

2.2.2 IAEA Inventory Verification and Inspection ................................................. 2.11

2.2.3 Containment and Surveillance..................................................................... 2.13

2.2.4 Additional Protocol ...............................................................................2.13

2.2.5 Necessary Conditions for Safeguardability - Facility Misuse …......................2.15

3.0 Technology Challenges and Recommendations .............................................................. 3.1

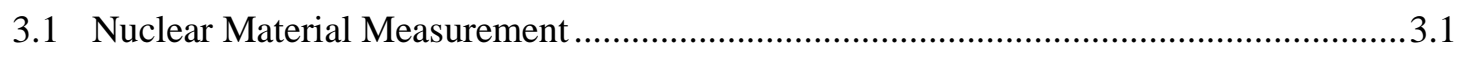

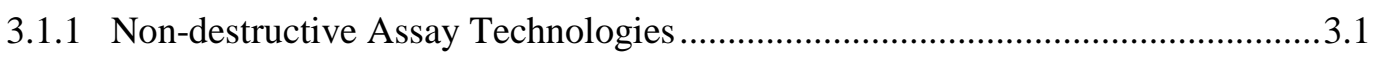

3.1.2 Destructive Assay Technologies .................................................................... 3.2

3.2 Enhanced Containment and Surveillance …........................................................... 3.3

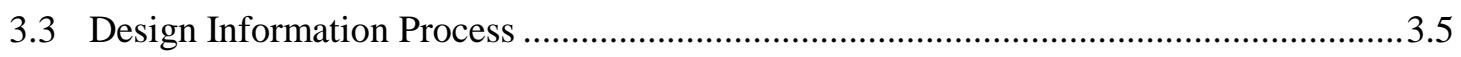

3.4 Environmental Sampling and Analysis ................................................................... 3.6

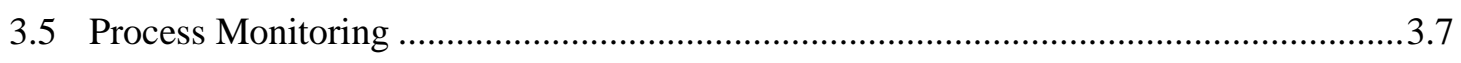

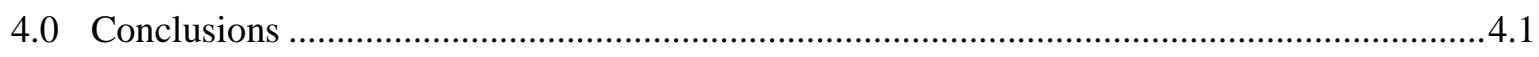

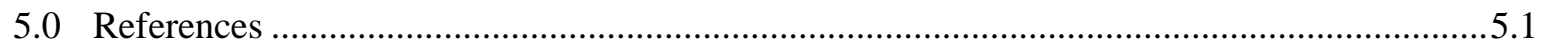

Appendix A Information/Technology Protection Measures at Current GCEP ...............................1 


\subsection{Introduction and Background}

The National Nuclear Security Administration (NNSA) is exploring and developing innovative safeguards approaches for nuclear facilities to increase the effectiveness of applied safeguards measures, and/or provide significant safeguards-related cost reduction for either the International Atomic Energy Agency (IAEA) or the facility operator without sacrificing effectiveness. As part of the Next Generation Safeguards Initiative (NGSI), NNSA asked Pacific Northwest National Laboratory to investigate whether a safeguards approach can be developed for "black box" processes or facilities.

A black box process or facility is one where inspector access is limited or entirely precluded because of the use of proprietary or classified technologies, safety, or inaccessibility. As new processes for enrichment or reprocessing are developed, limitations on inspector access may make consideration of black box facilities more common. The goal of this study was to determine whether standard application of IAEA safeguards measures to these black box processes and facilities permits the IAEA to draw valid conclusions as to the absence of diversion of nuclear materials and facility misuse. In cases where definitive limitations hinder the IAEA's ability to draw valid conclusions, the authors discuss advanced technologies or methodologies that could allow it to fulfill its verification responsibilities at black box facilities.

\subsection{Black Box Processes and Facilities}

The extent of the black box could range from a small portion of the facility to the entire facility. A facility could contain one or more black box processes or areas. This study primarily considers individual black box processes, as it is expected that for facilities with multiple black box processes, the overall facility safeguards approach could be assembled from the safeguards approaches for each individual black box process and any remaining facility processes. ${ }^{1}$

In the case where an entire facility is considered a black box, early and frequent communication between the State, designer, operator, and the IAEA is necessary to ensure that the IAEA can confidently draw a conclusion that all material within the State was used for peaceful purposes and that no undeclared production has occurred.

The primary conditions that warrant the demarcation of a black box are defined by information protection or safety requirements. There are some facilities with processes that are simply physically inaccessible to inspectors for the purpose of viewing or sampling as such activities would disrupt the integrity of the process underway. Information protection requirements are established by the State or operator whose facility employs proprietary, sensitive, or classified technologies, processes, or equipment. In these cases, the State and operator have access to the black box, but the IAEA has limited, or no access to perform inspection activities. In the context of nuclear fuel cycle facilities, safety requirements typically originate from the presence of environments deemed hazardous by the IAEA, State, or operator, such as areas with high radiation fields. In these cases, the same access limitations

\footnotetext{
${ }^{1}$ Facilities with multiple black box processes may have diversion or misuse paths that combine specific aspects of individual black box processes. This must be addressed in the development of safeguards approaches for such facilities; but that analysis would unnecessarily complicate this analysis. It is likely that safeguards approaches discussed here for individual black box processes will also be a significant component of the safeguards approach developed such facilities.
} 
apply to the State, operator, and IAEA. It is conceivable that a facility could house processes that require a black box area for both radiation and information protection purposes. In this case, the IAEA may have full access, limited access, or be prohibited from process or facility design information.

The IAEA currently safeguards facilities that contain black box areas that encompass process areas. However, as new process and facility designs are developed that employ new technologies, information security considerations may make it difficult for the IAEA to employ current techniques for verification. Some of these processes and technologies may also create radiation hazards that limit the IAEA's capacity for verification. Other black box facilities may contain design or configuration information that is considered propriety or proliferation sensitive. Examples of such facilities are gas centrifuge enrichment plants (GCEPs) and laser enrichment plants. In this case, the IAEA access to design information may also be limited. 


\subsection{Effects of Black Box Constraints on Safeguards Measures}

The IAEA implements safeguards to provide for the timely detection of the diversion or undeclared production of a significant quantity of nuclear material and the deterrence of such behaviors. This section briefly describes the safeguards measures and the way that these measures are affected by the constraints associated with black box processes or areas. The authors also suggest compensatory measures to address these constraints.

This section is divided into two parts. The first part discusses safeguards measures to detect diversion. The second part discusses safeguards measures for detection of facility misuse. Diversion is the covert removal of declared special nuclear material from declared activities or the use of this material for undeclared purposes. Facility misuse refers to reconfiguration of a declared facility for undeclared activities, such as enrichment of material beyond the stated enrichment level, or use of declared facilities for processing of undeclared nuclear material (IAEA 2002, IAEA 2008).

\subsection{Safeguards Measures for Detection of Diversion}

Measures for detection of diversion include: nuclear material accounting and control; IAEA inspection; containment and surveillance; and design information examination and verification. This section is organized to reflect the importance of each safeguard measure in detecting diversion.

\subsubsection{Nuclear Material Accounting and Control}

The fundamental diversion detection measure is nuclear material accounting and control (NMAC). ${ }^{1}$ For NMAC, the operator or State draws a nuclear material balance for a predetermined material balance area (MBA) to determine whether all nuclear material in that MBA is accounted for. The frequency of this closure, or material balance period (MBP), is determined by the State and operator, but the MBP must also satisfy IAEA requirements for allowable material uncertainties and detection timeliness within that defined period. The safeguards regulatory authority (SRA) submits reports to the IAEA that detail measurement of nuclear material that traverses an MBA boundary and nuclear material that is stored within the MBA. The IAEA reviews these reports and performs verification activities at the facility to determine whether the calculated material unaccounted for (MUF) in the MBA, and its associated measurement uncertainty, or $\sigma_{\mathrm{MUF}}$, are within allowable tolerances. These verification activities provide assurance that nuclear material has not been diverted to undeclared uses or locations. (IAEA 2002, IAEA 2008)

\subsubsection{Black Box Process or Area Constraints on Nuclear Material Accounting and Control}

The operator or State is not constrained in performing NMAC activities within black box processes or areas to which IAEA access is limited by information protection requirements. In these cases the operator

\footnotetext{
${ }^{1}$ At the State level, a States' system of accounting for and control of nuclear material (SSAC) is required to be established in accordance with INFCIRC/153 (IAEA 1972).
} 
or State discloses accountancy information to the IAEA, but this information may not be complete from the perspective of the IAEA. For example, the operator or State may not provide NMAC information that could reveal sensitive design information.

For processes or areas to which access is limited by radiation protection requirements, physical inventories are constrained to use of measurement methods that can be conducted remotely (e.g., remote sampling or monitoring and volume measurements, hot cell analysis of samples, etc.). Measurements of highly radioactive transfer streams are also constrained to methods that can be conducted remotely.

\subsubsection{Compensatory Measures for Black Box Constraints on Nuclear Material Accounting and Control}

When IAEA access to areas or processes is prohibited because of information protection requirements, the IAEA will need to conduct NMAC activities immediately outside the MBA boundaries as a compensatory measure.

Black box processes or areas to which access is limited by radiation protection requirements can best be overcome during negotiation of the facility attachment when MBA boundaries are defined. To the extent practical, MBAs should be defined in a way that incorporates only the facilities and processes for which access is not available. The MBA should minimize the number of penetrations, or material transfer routes into and out of the MBA, to limit the number of ways in which material can be removed.

Should the inputs and outputs (including measured discards) from these areas be material forms that cannot be accurately measured, then it may be necessary to enlarge the MBA to include the additional process steps required to convert the special fissile material to a form that can be more accurately measured.

Additional mitigation measures for black box processes or areas to which access is limited by radiation protection requirements include design measures to facilitate remote sampling, monitoring, and volume measurements. These include design features (e.g., spargers for vessels containing aqueous solutions) to ensure the homogeneity of the materials to be sampled. They also include design of tanks or process vessels to facilitate accurate volume measurements of highly radioactive materials outside of the black box area.

\subsubsection{IAEA Inventory Verification and Inspection}

The IAEA inspection activities related to detecting diversion are primarily focused on verifying that the operator or State NMAC activities properly documents the physical inventories and transfers that compose the material balance. The inspection activities include verification of the physical inventory taken by the State or operator and changes to the inventory. These verification activities may be accomplished by supplementing regularly scheduled inspections with unannounced, short notice, or random inspections (IAEA 2002, IAEA 2008). The IAEA also inspects to ensure that the facility has not been modified in ways that degrade the effectiveness of NMAC or containment or surveillance measures. These factors are addressed in the discussion of design information examination and verification in Section 2.1.6. 


\subsubsection{Black Box Process and Area Constraints on IAEA Inventory Verification and Inspection}

Black box processes and areas limit inspector access to physical inventory items for verification and hinder IAEA verification of inter-MBA transfer measurements. The overall effect of these constraints depends, in part, upon the nature of the black box process. If the material balance is inventory-dominated (i.e., the beginning and ending inventories are large in comparison to the total material transferred into and out of the MBA during a MBP), then the main constraint relates to inspector capability to verify the physical inventory for the black box. If the material balance is throughput-dominated (i.e., the total material transferred into and out of the MBA during a MBP is large in comparison to the beginning and ending inventory), then the main constraint relates to inspector capability to verify measurements of transfers into and out of the MBA. It is possible that the material balance will not be inventory- or throughput-dominated, in which case attention must be paid to the constraints on verification of both physical inventory and transfer measurements.

\subsubsection{Compensatory Measures for Black Box Constraints on IAEA Inventory Verification and Inspections}

Compensatory measures discussed in this section focus on determining whether facility anomalies or losses are occurring within black box areas. To make this determination, MBA boundaries must be defined so that they encompass only the black box process locations to the maximum extent practicable. The State and operator should then work with the IAEA to create a managed access plan that allows verification activities of nonsensitive or safe areas that may share the MBA with the black box process or equipment. The State should be encouraged to limit the area to which access is restricted and confine the area with a physical barrier with the minimum number of penetrations. This practice reduces the number of items that must be covered by surveillance or monitoring for detection of covert movement of nuclear material into or out of the MBA. To the extent practicable, the inventory and flow key measurement points (KMPs) should be located outside of the physical barrier to permit inspector verification of physical inventory and transfers (inventory changes).

The safeguards impact of the inability to perform physical inventory verification (PIV) within a black box area could be mitigated by removing items created for inventory (e.g., containers under operator or State's system of accounting for and control of nuclear material [SSAC] seal) from the black box area for inspector verification. If this approach were employed, measures would need to be taken to prevent operator or State deception. For example, to disguise loss, the operator could present the same nuclear material in several different containers for verification. The IAEA could preclude this kind of deception by requiring all such items be removed to an area accessible to IAEA inspectors until the PIV is completed. If this were not possible, the IAEA inspector could apply IAEA seals to containers as they are verified and, near the conclusion of the PIV, request access to previously verified and IAEA-sealed containers to verify that they had not been tampered with. The PIV on this material can also be used by the inspector to assess the measurement uncertainty associated with the measurement systems used by the operator or State.

The effectiveness of this mitigation measure would be limited if the operator could not remove some of the material (e.g., holdup) from the black box area for PIV. Black box processes should therefore be designed to minimize process elements with potential for process holdup. Furthermore, process and equipment design that facilitates cleanout after shutdown would aid IAEA verification by reducing the 
amount of holdup in process, enabling the operator to properly account for all material in the facility. Interaction between the State, operator, and IAEA to identify and mitigate these types of process design issues during facility design is especially important for black boxes to which access is limited by radiation protection requirements.

Regardless, there always will be some holdup material that cannot be removed from the black box area for PIV. However, if the sum of the holdup and the calculated MUF for the facility are with acceptable uncertainty tolerances, ${ }^{2}$ then the IAEA can reach a conclusion that no material has been (abruptly) diverted from that MBA. This is likely to be the case for processes in which most of the inventory can be verified by the inspector (low holdup) or processes where the inventory is relatively low (throughput dominated processes like gas centrifuge enrichment) compared to the significant quantity. ${ }^{3}$

Protracted diversion (over several inventory periods) can be detected by statistical trend analysis of cumulative MUF and the quantities of nuclear material not subject to PIV measurement. The latter quantity of material should be expected to be approximately normally distributed around its mean and not exhibit statistically significant trends after the first few inventory periods.

\subsubsection{Containment and Surveillance}

Containment and surveillance $(\mathrm{C} / \mathrm{S})$ measures are used by the IAEA to maintain continuity of knowledge on the integrity of safeguards-relevant data or material and the movement of safeguarded material. In the context of black box areas within a facility, physical containment barriers bound the MBA and direct material through flow KMPs to prevent undeclared movement of nuclear material into or out of the MBA. Where appropriate, surveillance measures monitor physical transfers and correlate them to material measurements at the flow $\mathrm{KMP}^{4}$ (IAEA 2002, IAEA 2008).

\subsubsection{Black Box Process or Area Constraints on Containment and Surveillance}

For black box areas where access is constrained by information protection requirements, the IAEA would have limited, if any, ability to install and verify the effectiveness, integrity, or operation of C/S measures. Any installed surveillance equipment would likely have a constrained field of view to prevent release of sensitive information about the equipment or process. Information protection requirements may also mandate that sensitive components being transferred to or from the black box area be shrouded or packaged during movement, preventing visual verification that nuclear material is not being removed with the sensitive components.

For black box areas where access is limited by radiation protection requirements, similar constraints apply. The State, operator, and IAEA would not have access to the black box, limiting IAEA ability to verify seal integrity during subsequent inspections. The IAEA would have no ability to verify the

\footnotetext{
${ }^{2}$ Procedures for calculating MUF and its uncertainty can be found in Safeguards Technical Report, "Material Balance Evaluation," IAEA Department of Safeguards, April 2002.

${ }^{3}$ For high throughput processes care will need to be taken to verify measured inventory changes, employing measures like shipper-receiver-difference verification and short-notice or no-notice inspections. So long as the flow key measurement points are located outside the area to which inspector access is precluded, the information protection requirements do not affect these measures.

${ }^{4}$ IAEA generally considers surveillance to involve visual surveillance only. Thus, radiation or process flow monitoring does not fall within the IAEA's use of the word.
} 
integrity and operation of installed surveillance equipment. Without access to the black box to repair or replace equipment, the IAEA could not verify the removal of material shrouded by shielded containers from the black box.

Black box area access limitations of either type also constrain the ability of the inspector to verify the continued integrity of structures internal to the black box (e.g., the floor of an MBA that is at ground level) used to ensure the containment of the black box.

\subsubsection{Compensatory Measures for Black Box Constraints on Containment and Surveillance}

Safeguards approaches should minimize use of C/S measures, to the extent practicable, within the black box area due to the limitation of inspector access for installation and verification of such measures. This means that the State and operator should work to design a black box area as a single MBA that only limits access to the necessary components or process areas. Process or equipment design should be such that flow and storage KMPs can be located outside of the black box and include containment barriers. These would serve to direct people and material to these KMPs to preclude illicit transfer of nuclear material into and out from the black box area.

Even with this configuration, the operator will likely need to transport shrouded or packaged equipment into and out of the black box area. Shrouding and packaging protect sensitive design information and protect personnel against radiation. In either case, $\mathrm{C} / \mathrm{S}$ measures alone will not be sufficient to detect movement of undeclared nuclear material. The process for making these transfers should be established during the design phase, and information about the design of the container or shroud assembly should be shared with the IAEA to the extent possible. The IAEA can use this information to develop safeguards measures capable of verifying that the transfer is not being used to surreptitiously insert or remove nuclear material (see Section 3 for technology recommendations).

Containment and surveillance measures could also be used to address vulnerabilities associated with penetrations to the black box. Undeclared penetrations of the containment barrier could be used to surreptitiously move nuclear material into and out of the black box area. IAEA efforts to detect such activities would be impeded if the physical and visual access limitations to the black box area preclude detection of process modifications, installation of additional equipment for material movement, or the creation of undeclared penetrations. The IAEA could use surveillance or monitoring to detect the type of activities that an operator might employ to disguise the creation of such undeclared penetrations (e.g., heavy maintenance). In this case, such monitoring could be supplemented with a managed access plan that is negotiated between the IAEA, the State, and operator to verify containment integrity after the work is completed. For declared penetrations, the installation of seals (e.g., for infrequently used doors) or monitoring equipment (e.g., for ventilation duct work) on the outside of the containment barrier can detect undeclared movement of material.

\subsubsection{Design Information Process (Examination and Verification)}

Within the context of diversion detection, the focus of design information examination (DIE) and design information verification (DIV), also referred to as design information process, is making sure that the measurement systems and measurement controls in the NMAC system provide adequate capability to detect the diversion of a significant quantity of nuclear material in a timely manner. The DIE/DIV 
process also ensures that adequate $\mathrm{C} / \mathrm{S}$ measures can be implemented to ensure the integrity of the NMAC system will be maintained and adequate provisions have been made for inspectors to verify the components of the material balance.

As part of the DIE, the State or operator submits design information to the IAEA on new nuclear facilities during the design and construction phase of the new facility. Design information includes the facility description; the form, quantity, location and flow of nuclear material being used; facility layout and containment features; and procedures for nuclear material accountancy and control. Among other things, this information is used by the IAEA to design the facility safeguards approach, determine material balance areas and select key flow and inventory measurement points and other strategic points, develop the design information verification plan, and establish the essential equipment list. Any changes that are relevant to safeguards are also provided to the IAEA until the facility is decommissioned for safeguards purposes (IAEA 2002, IAEA 2008).

During DIV, the IAEA visits the facility to verify the correctness and completeness of the design information provided by the State or operator and confirms that the facility is built as declared. Periodic DIVs are performed, sometimes in conjunction with routine inspections, to confirm that the safeguards approach remains appropriate, and that any changes to the facility do not degrade the effectiveness of applied safeguards measures such as the NMAC system and $\mathrm{C} / \mathrm{S}$ measures.

\subsubsection{Black Box Process or Area Constraints on the Design Information Process}

To support the design information process, the design and layout of the black box process or area must permit the installation and operation of $\mathrm{C} / \mathrm{S}$ measures to monitor transfers of nuclear material and ensure that transfers of sensitive or radioactive equipment into and out of the black box process MBA cannot be used to conceal transfers of undeclared nuclear material. The design and layout must also permit inspector verification of the measured values of the material in the black box process MBA, with the exception of the quantity of nuclear material on inventory identified as unverifiable in the design information submittal.

For black box process areas where the limitations are imposed for radiation protection reasons, the access limitations are not expected to affect the submittal of design information. Examination, and subsequent verification, of any design information under these requirements will require inspector access to the black box area prior to the creation of hazardous conditions. For black box process areas where the limitations are imposed for information protection, it is expected that the State will submit as much design information as practical without violating information protection requirements. The more extensive the design information submitted about a black box process or area, the more options there are likely to be for developing a safeguards approach. Black boxes that encompass entire facilities, precluding the provision of any design information, cannot be adequately safeguarded without significant compensatory measures, as the design information process is the foundation from which safeguards approaches can be structured to ensure the absence of diversion.

Once sensitive equipment is installed, or radioactivity limits IAEA access, inspectors will not have access to black box process for design verification. In some cases special procedures may permit IAEA access to certain areas with shrouding of sensitive equipment and processes. 


\subsubsection{Compensatory Measures for Black Box Constraints on the Design Information Process}

As part of the DIE process, the State should be encouraged to provide as much information as practicable, within the constraints imposed by information protection requirements. Specifically, the estimate of uncertainty in MUF, the type and form of nuclear material that will flow through the facility, and the estimated quantity of nuclear material on inventory that cannot be verified by IAEA inspectors as a part of physical inventory verification can be used to establish whether the black box process can be safeguarded. For example, in order to divert a significant quantity in the "unverifiable inventory," the State or operator must divert an additional quantity of nuclear material that is equal to the difference between the significant quantity and the unverifiable inventory. If the NMAC system has sufficient power to detect the diversion of this difference, referred to here as the "test statistic," in a timely fashion, then the IAEA can draw a valid conclusion that nuclear material has not been diverted from the black box process. $^{5}$

The focus of DIV would be to ensure that all penetrations of the physical barriers surrounding the MBA have been constructed as specified in the submitted design information and that there are no undeclared penetrations. The inspector should determine the surveillance and other safeguards measures that would detect creation of undeclared penetrations. Special attention should be given to portions of the physical barrier where undeclared barrier penetrations would not be readily visible outside the material balance area (e.g., ceiling penetrations into the area between building floors or the ceiling and roof, floor penetrations into the area between building floors or that continue underground, or wall penetrations into the area between rooms). Depending upon the process layout, it may be possible to provide visual access within the black box area to those portions of the containment barrier that cannot be accessed outside the black box area. This visual access might be provided by use of an IAEA camera operated by facility operations or State personnel. The secondary focus of the initial design verification will be ensuring that the as-built facility has not changed in ways that degrade the effectiveness of the containment or surveillance measures.

For black box areas where radiation protection requirements limit inspector access, the IAEA should be able to perform an initial design verification before the facility begins processing highly radioactive material. This may also provide an opportunity to install radiation resistant monitoring equipment. For black box areas where access is limited by information protection requirements, the IAEA should be able to perform a limited design verification before the sensitive equipment is installed. They should inspect the interior of the material balance black box area prior to installation of the sensitive equipment and controls. Subsequent design verification activities over the life of the facility will be focused on examination of the outside of the physical barrier to ensure that additional barrier penetrations have not been installed and the as-built facility has not changed in ways that degrade the effectiveness of the containment or surveillance measures.

If the IAEA is unable to perform independent verification of any NMAC measurements for the black box area, it cannot safeguard the facility. However, in certain cases, it might be possible for the IAEA to rely upon complementary safeguards measures, such as C/S. For such an approach to be effective, the

\footnotetext{
${ }^{5}$ Note that, although a single diversion can theoretically be concealed in this manner, attempts to conceal multiple diversions (protracted diversion) in this manner will be revealed by a cumulative sum test of the MUF series or by an increasing trend in the quantity of inventory that cannot be verified by IAEA inspectors.
} 
material form for the black box process would need to be such that a significant quantity of the declared nuclear material occupies such a large volume that detection of the loss of anything approaching a significant quantity would be likely with $\mathrm{C} / \mathrm{S}$ measures. In order for the IAEA to rely upon such measures, the State would need to provide sufficient design information so that the IAEA could ensure that the operator was not able to process nuclear material into an undeclared form that occupied a significantly smaller volume. The State would also need to provide sufficient information about routine process flows for the IAEA to determine clearly detectable indications of undeclared activities to compare to surveillance observations.

If the IAEA determines that the black box process or area still cannot be safeguarded, then design changes need to be considered to reduce measurement uncertainty, reduce the holdup and in-process inventory not subject to IAEA verification, or increase the inventory frequency to improve diversion detection. From the perspective of diversion detection, it might be possible to safeguard such a black box facility based upon shipper and receiver verification if the estimated facility inventory was much less than the IAEA significant quantity for the type of material processed and shipper and receiver data from other safeguarded facilities were available in a sufficiently timely manner for the form of material processed. Such a facility would not be safeguardable from a facility misuse perspective because it would be impossible to draw a valid conclusion that the facility had not processed undeclared nuclear material, which would be outside the NMAC system providing reports to the IAEA.

Finally, in cases where information is sensitive because of proliferation concerns rather than commercial or proprietary concerns, it may be possible for the IAEA to establish an agreement for review of the design information for the black box process or area under special security controls. For example, access to the information could be granted only to reviewers who were appropriately cleared personnel from nuclear weapon states.

\subsubsection{Necessary Conditions for Safeguardability - Diversion Detection}

The analysis presented in this section establishes the following as necessary conditions for safeguardability from the perspective of diversion detection. That is, the following conditions must be met in order for the IAEA to draw a valid conclusion that nuclear material has not been diverted from the black box process:

- The black box process is located within an area of the facility that is surrounded by a containment physical barrier and has been defined as an MBA. The transfer key measurement points for the black box process MBA are located outside of the containment physical barrier and are accessible for IAEA inspection.

- The NMAC system has sufficient power to detect the loss or diversion of the "test statistic" from the black box process MBA in a timely fashion.

- The design and layout of the black box process or area permits inspector verification of the measured values of the material balance components for the black box process MBA, with the exception of the quantity of nuclear material in inventory identified as unverifiable in the design information submittal.

- The design and layout of the black box process or area permits the installation and operation of C/S that provides assurance that all physical transfers and all transfers of nuclear material are reflected in 
the NMAC system, including measures to ensure that transfers of sensitive or radioactive equipment into and out of the black box process MBA cannot be used to conceal transfers of undeclared nuclear material.

- The design and layout of the black box process or area permits design verification by inspector examination or other means to ensure that no undeclared penetrations have been made to the physical barrier surrounding the black box area.

- The design and layout of the black box process or area permits inspector design verifications to ensure that the as-built facility has not changed in ways that degrade the effectiveness of the containment or surveillance measures.

\subsection{Safeguards Measures for Detection of Facility Misuse}

Measures for detecting facility misuse include: design information examination and verification, IAEA inspection, containment and surveillance, and measures available under the Additional Protocol (AP). This section is organized to reflect the importance of each safeguard measure in detecting misuse. Measures under the AP are discussed separately as they only apply in States where an AP is in force.

\subsubsection{Design Information Process (Examination and Verification)}

The design information process, supplemented by related inspection activities, is the primary measure relied upon to detect facility misuse. During design information examination, the IAEA determines whether or how the facility could be reconfigured to conduct undeclared activities, with primary focus on activities that change the type or form of nuclear material in a way that makes it more attractive for proliferation. The design examination includes reviewing the black box process and layout information to identify misuse paths (scenarios) and indicators for all planned configurations, developing a safeguards approach to close the misuse paths or detect their use, identifying undeclared process reconfigurations, and monitoring the misuse indicators. This review is more complex for facilities or processes designed to be reconfigurable. In this case, the design information provided by the State also needs to include a description of all planned process configurations, the initial process configuration, and any commitments to notify the IAEA when the configuration changes.

The focus of design information verification is to ensure that the facility or process has not been reconfigured or operated in a manner to permit undeclared activities. DIVs also focus on ensuring that the as-built facility has not changed in ways that degrade the effectiveness of the physical barriers, containment, surveillance, or other measures used in the safeguards approach to preclude misuse. The DIV also focuses particularly on detection of undeclared penetrations in physical barriers or degradation of $\mathrm{C} / \mathrm{S}$ measures that could permit introduction or removal of undeclared material. These activities are much more challenging when inspector access to the area or process equipment is restricted because of information protection or radiation safety requirements.

\subsubsection{Black Box Process/Area Constraints on the Design Information Process}

For black box process areas where the limitations are imposed for radiation protection, access limitations are not expected to affect the design information submittals. For black box process areas where the limitations are imposed for information protection, the State or operator will not provide 
sensitive design information. These information gaps are likely to increase the difficulty of identifying misuse paths, indicators of misuse, and undeclared process reconfigurations.

Once sensitive equipment is installed, for areas where access is limited by information protection requirements, or once processing of highly radioactive material begins, access to black box processes areas for design verification to identify undeclared process or facility reconfiguration will be restricted. Special procedures or compensatory measures will be required to verify that misuse is not occurring.

\subsubsection{Compensatory Measures for Black Box Constraints on the Design Information Process}

As discussed in Section 2.1.4.2, it is important for the State to provide to the IAEA as much relevant information as practicable about the black box design early in the design process. ${ }^{6}$ In addition to the information typically provided to the IAEA, facilities with black box processes constrained by information protection requirements should be required to identify the portions and locations of the process equipment that are not sensitive and that could be monitored or possibly inspected under complementary access measures to provide assurance that the process has not been reconfigured. The design information submittal should also describe the design provisions that the State or operator have made to accommodate initial and periodic design information verification in the black box area.

Information protection requirements will significantly constrain the ability for the IAEA to perform design information verification in the black box area. Thus, design verification of the facility before the installation of sensitive equipment could allow the inspector to verify that there are no undeclared containment barrier penetrations that could permit the introduction or removal of undeclared material. Scheduling the installation of all sensitive equipment and materials as late as practicable in construction would also enable the IAEA to verify that the construction conforms to as much of the nonsensitive elements of the design information reported to IAEA as practicable. This mitigation measure will need to be negotiated with the State or operator and would require flexibility and responsiveness in the deployment of IAEA inspectors to minimize impact on the construction schedule.

If the inspector is prohibited from accessing the MBA for radiation protection purposes, the IAEA should be able to perform an initial design information verification before the facility begins processing highly radioactive material. This may also provide an opportunity to install any radiation resistant monitoring or surveillance equipment. It also may be possible to provide visual access within the black box area to those portions of the containment barrier that cannot be accessed outside the black box area. This visual access might be provided by an IAEA camera operated by facility operations or State personnel. An inspector might also focus on possible misuse indicators that can be detected outside the black box process area, such as NMAC anomalies, environmental sampling evidence of undeclared material types, or indicators of process anomalies, such as unusual utility usage. Ultimately, the IAEA will need to determine whether the information that has been provided is sufficient to identify misuse paths (scenarios) and indicators, for all planned process configurations. Early provision of design information would also help the IAEA identify undeclared process reconfigurations, preclude or detect

\footnotetext{
${ }^{6}$ As noted, it may be possible for the IAEA and the State to establish protocols for IAEA information protection to enable the State to provide additional sensitive information.
} 
initiation of undeclared activities, and monitor misuse indicators. ${ }^{7}$ Using Safeguards by Design approaches may increase the likelihood of a process design that is sufficiently transparent for the IAEA to develop an effective safeguards approach (Bari et al. 2012).

In cases where facility reconfiguration can be accomplished in a relatively short time, design verification must be accomplished as a part of short-notice or no-notice inspections. Such inspections deter or detect attempts to reconfigure the design to permit misuse and then return to the declared configuration prior to IAEA inspection (IAEA 2002, IAEA 2008). Subsequent installation of C/S or other equipment could enable the IAEA to verify that the black box process has not been reconfigured to permit misuse. ${ }^{8}$ For example, an IAEA camera can be installed to photograph the piping or valve configuration of the process to verify that it was unchanged. ${ }^{9}$

If the process equipment can be designed in a way that all credible misuse strategies require reconfiguration ${ }^{10}$ of nonsensitive portions of the equipment or physical barriers, it may be possible to shroud sensitive equipment or sensitive portions of the equipment to permit limited inspector access for design verification purposes. There may also be approaches where remote cameras (in high-radiation fields) or cameras operated by facility personnel could provide photographs to the IAEA of portions of equipment that would need to be reconfigured for credible misuse strategies. Such approaches would need to be carefully developed to permit detection of falsification of the photographs (e.g., use of tampersafe IAEA cameras and time stamp information internal to the camera and in the external photographic field of view to ensure that the photo reflected conditions at the time of the inspection). Safeguards by Design principles would facilitate such an approach. (Bari et al. 2012)

\subsubsection{IAEA Inventory Verification and Inspection}

IAEA inspection activities can supplement design information activities to provide assurance that misuse has not occurred. These include verification of the operability of any $\mathrm{C} / \mathrm{S}$ measures relied upon in the safeguards approach to preclude misuse. They may also include review of State or operator NMAC information to identify unusual variations in process yields, waste or scrap streams, or other process streams that are indicative of misuse. IAEA inspections may also include measures such as

\footnotetext{
${ }^{7}$ The review needs to consider the detection or elimination of misuse scenarios where undeclared material is produced and staged within the black box area pending a "breakout" accompanied by renunciation of IAEA safeguards. The main concern here is with detection of illicit staging areas. As long as the introduction of undeclared material can be precluded / detected, transfer measurements can be verified, and adequate physical inventory measurement verification can be accomplished. The stockpile of undeclared material will be detected as a material balance anomaly (e.g., MUF or presence of undeclared material on inventory).

${ }^{8}$ It may be possible to use remote or unattended NDA equipment installed by the State or operator in the black box area provided the IAEA can obtain adequate assurance that the equipment is installed in an manner so that it provides effective monitoring of what it is intended to monitor.

${ }^{9}$ In order for this approach to be effective, the design information submittal would need to provide sufficient information to demonstrate that misuse would require changes to the configuration of the equipment or physical barrier photographed, the field of view of the photograph would need to exclude sensitive equipment to which IAEA visual access was prohibited, and the photographic process would need to preclude surreptitious tampering with the IAEA photographic equipment and to verify that the resultant photo actually showed the configuration of the equipment at the time of the inspection.

${ }^{10}$ In this case, reconfiguration of process equipment includes the addition of undeclared processes or lines inside the black box area.
} 
environmental sampling to detect the presence of undeclared nuclear material types or forms (IAEA 2002, IAEA 2008).

\subsubsection{Black Box Process or Area Constraints on IAEA Inventory Verification and Inspections}

Measures, like C/S, deployed within the black box area to detect the presence of undeclared nuclear material types or forms may also be constrained. For example, the restriction of inspector access to an area or process equipment because of information protection or radiation safety requirements may preclude or limit environmental sampling in that area.

\subsubsection{Compensatory Measures for Black Box Constraints on IAEA Inventory Verification and Inspections}

The verification of the integrity and operability of most C/S measures outside of the black box area is not impeded by the access limitations imposed by information protection or radiation protection requirements. An important exception is the verification of the physical barrier surrounding the black box area. All areas of this barrier may not be physically or visually accessible from outside the black box area. For example, if the black box area is on the lowest floor of a facility, the floor barrier is not physically or visually accessible from outside the black box area (e.g., an undeclared tunnel into the black box area would not be readily detectable). Strategies to compensate for this limitation are discussed in Section 2.1.4 addressing design examination and verification.

IAEA inspections may also include measures to detect the presence of undeclared nuclear material types or forms. The check for undeclared nuclear material types or forms may occur using environmental sampling performed during inspections to verify of physical inventories or material transfers. In addition to building surfaces outside the black box area, environmental samples may be taken from filters in the heating ventilation and air-conditioning system serving the black box area. If this measure is to be relied upon to detect facility misuse, the filter housings should be designed to facilitate environmental sampling while maintaining radiological contamination control. Alternatively, monitoring equipment may be designed with the capability of detecting the presence of undeclared nuclear material types from outside the filter housing via non-destructive assay (NDA) methods.

Although the IAEA may be able to negotiate more extensive environmental sampling locations when the State needs to limit inspector access to facility processes, early involvement in the design may permit the IAEA to achieve both the information protection needs of the State or operator and the information needs of the IAEA by designing safeguards into the process (Bari et al. 2012). The potential combination of restricted inspector access to sensitive processes and expanded access for environmental sampling may make environmental sampling an even more useful safeguards measure in this case. ${ }^{11}$

\footnotetext{
${ }^{11}$ Paragraph 76 of INFCIRC/ 153 provides that, "In the event of the State concluding that any unusual circumstances require extended limitations on access by the IAEA, the State and the IAEA shall promptly make arrangements with a view to enabling the IAEA to discharge its safeguards responsibilities in the light of these limitations." (IAEA 1972) In addition, Paragraph 73 of INFCIRC/153 provides that the IAEA may make special inspections if the "information made available by the State ... is not adequate for the Agency to fulfill its responsibilities." (IAEA 1972) These provisions may permit complementary access, including environmental sampling even in a State that is not an Additional Protocol signatory.
} 


\subsubsection{Containment and Surveillance}

Containment and surveillance also play a role in detection of facility misuse by providing physical barriers to process reconfigurations associated with misuse and providing surveillance to detect such process reconfiguration activities.

\subsubsection{Black Box Process and Area Constraints on Containment and Surveillance}

Black box areas access limitations constrain inspector verification that the integrity of containment barriers and the surveillance devices within the black box area has been maintained. Although physical barriers in the black box process area may impede or preclude process reconfiguration, the inability to inspect such barriers means that their integrity must be verified by a means other than direct inspection. Similarly, the integrity of surveillance devices to detect process reconfiguration or misuse must be verified by a means other than direct inspection.

\subsubsection{Compensatory Measures for Black Box Constraints on Containment and Surveillance}

For black box areas where access is constrained by information requirements, there are likely to be constraints on the installation and maintenance of containment and surveillance equipment located within the black box area. There also are likely to be constraints on the field of view of any surveillance equipment observing locations within the black box areas. Similar considerations apply for black box areas where access is constrained by radiation protection requirements. The maintenance of such equipment will affect ALARA (as low and reasonably achievable) requirements and equipment reliability is likely to be adversely affected by the radiation fields. For these reasons, the safeguards approach should minimize, to the extent practicable, reliance on containment and surveillance equipment located within the black box area. In some cases it may be possible to employ process monitoring in lieu of surveillance. In other cases, it may be possible to design the layout of sensitive equipment in black box areas to permit limited surveillance of equipment that would need to be modified during process reconfiguration or of containment barriers relied upon to prevent or impede process reconfiguration. In such cases, care would be needed to ensure that tampering with $\mathrm{C} / \mathrm{S}$ equipment or with the information reported by the $\mathrm{C} / \mathrm{S}$ equipment would be detectable.

\subsubsection{Additional Protocol}

The AP was created to expand the legal authority of the IAEA under its safeguards agreements in order to strengthen the effectiveness and improve the efficiency of IAEA safeguards. Under the AP, the IAEA has at its disposal an expanded set of tools that allows the IAEA to verify not only the correctness of a State declaration, but also its completeness. Prior to the AP the IAEA had a difficult time verifying the absence of undeclared activities in a facility or state. The AP has worked to increase the amount of information available to the IAEA of activities that occur beyond the walls of safeguarded facilities in order to capture the state of nuclear and nuclear-related activities in the State as a whole (Doyle 2008). 


\subsubsection{Black Box Process and Area Constraints on Additional Protocol Measures}

Details regarding the complete set of safeguards measures under the AP can be found in the text of the Model Protocol Additional to the Agreement(s) Between State(s) and the Agency for the Application of Safeguards, INFCIRC/540 (Corrected) (IAEA 1997). Presented here is a discussion of only those measures negatively affected by black box constraints.

The measure of complementary access (CA) is affected the most by black box constraints. The IAEA uses CA to resolve questions or inconsistencies in declared information and to verify declared information to ensure the absence of undeclared material or activities at all buildings on a nuclear site, locations declared under the AP, and locations where the IAEA has identified a need for access. Facilities with black box areas, or black boxes that encompass entire facilities, affect CA in two ways. First, information protection constraints may increase the occurrence of inconsistencies in declarations as not all facility information is made available to the IAEA. Second, black boxes restrict inspector access, limiting the value of activities that can be carried out during a CA. These activities include nuclear material measurement, application of $\mathrm{C} / \mathrm{S}$ measures, environmental sampling, visual observation, and examination of records. As previously discussed in this report, black box constraints upon measures to perform these activities will affect the ability of the IAEA to verify State declarations, but under the AP such constraints upon CA restricts the ability of the IAEA to verify the completeness of declarations.

Also affected by black box constraints is the provision of information about all parts of the nuclear fuel cycle present in a State including mines, mills, wastes locations, and any other facility where nuclear material may be present. Any one of these facilities, or buildings on such sites, can contain a black box area or be fully encompassed by a black box. While the information provided under the AP about these facilities and buildings is limited in depth ${ }^{12}$ compared to the information submitted under comprehensive safeguards agreements, restriction of the information will nonetheless impede the ability of the IAEA to develop a complete picture of activities being performed in a State.

\subsubsection{Compensatory Measures for Black Box Constraints on Additional Protocol Measures}

The AP is a voluntary mechanism that complements a State's safeguards agreement, granting the IAEA wider access to information and facilities in States that have entered the protocol into force. In regards to black box processes and facilities, the loss of benefits gained from CA and the provision of additional information can only be counterbalanced with the availability of even more information regarding nuclear and nonnuclear related activities within a State. This is where the additional measures granted under the AP will come to play a larger role in ensuring the absence of undeclared material and activities.

Beyond facility and site boundaries, the IAEA is granted access to the following additional types of information under INFCIRC/540:

\footnotetext{
${ }^{12}$ Information declared under the AP includes: location; use or intended use, and contents of buildings on a declared site; operational status; scale of operations (manufacturing locations for Annex I items); capacity and annual production (in the case of mines and concentration plants); and the quantity and chemical composition of source material and its intended use.
} 
- the collection of environmental samples at locations beyond those declared when necessary and widearea environmental sampling (with IAEA Board of Governors approval and consultation with the State)

- information regarding the import, export, and manufacturing of sensitive nuclear-related technologies and verification of such information provided by a State

- information regarding government-sponsored and commercially funded nuclear-fuel-cycle-related research and development activities and future fuel cycle plans.

In concert with the introduction of the AP, IAEA capabilities in gathering and analyzing open source information (including satellite imagery and published literature such as books, scientific articles, and unclassified reports) also expanded. IAEA authorities for using open source information as part of its verification activities are not dictated by the AP. However, the vast quantity of information submitted by States under the AP (and other safeguards agreements) and open source information have accelerated the ability of the IAEA to construct a snapshot as to all activities taking place within a State. For black box process areas, the availability of such additional information for analysis by the IAEA would work to increase confidence in the IAEA conclusions regarding declared and undeclared activities under way within a black box. In instances where entire facilities are enclosed within a black box and the IAEA cannot be supplied design information for information protection requirements, at a minimum the State should have entered into force an AP with the IAEA. This will grant the IAEA access to more information that can be used to connect all other fuel cycle activities that may support the operation of the black box facility, giving the IAEA some ability to detect undeclared material or activities. Furthermore, it is likely that in such a situation the IAEA and State would negotiate the use of more invasive measures allowable under the AP, such as wide-area environmental sampling to further increase confidence in IAEA conclusions regarding the black box facility.

\subsubsection{Necessary Conditions for Safeguardability - Facility Misuse}

The analysis above establishes the following as necessary conditions for safeguardability from the perspective of facility misuse. That is, the following conditions must be met in order for the IAEA to draw a valid conclusion that the process has not been used for an undeclared purpose or to process undeclared material:

- The design information provided by the State is sufficient for the IAEA to identify misuse paths (scenarios) and indicators, for all planned process configurations.

- The design information is sufficient to develop a safeguards approach that closes the misuse paths, through design features or safeguards measures, or detects their use.

- The design information is sufficient to reliably identify undeclared process reconfigurations, preclude or detect initiation of undeclared activities, and monitor misuse indicators.

- The design and layout of the black box process or area permits the installation and operation of $\mathrm{C} / \mathrm{S}$ that provides assurance that undeclared process reconfigurations or the introduction of undeclared material into the process would be detected. 
- The design and layout of the black box process or area permits design verification by inspector examination or other means to ensure that no undeclared penetrations have been made to the physical barrier surrounding the black box area.

The design and layout of the black box process or area permits inspector design verifications to ensure that the as-built facility has not changed in ways that degrade the effectiveness of the containment or surveillance measures relied upon for detecting misuse in the established safeguards approach. 


\subsection{Technology Challenges and Recommendations}

As facility processes and technologies advance, technology that supports international safeguards must also improve. Although black box processes present complex and sometimes unique technical challenges to IAEA, there are efforts under way to resolve challenges highlighted as part of this study. The development and integration of technology areas discussed in this section will enable the IAEA to safeguard a wider range of black box facilities and to enhance safeguards effectiveness given information protection or radiation protection constraints.

\subsection{Nuclear Material Measurement}

Key to the NMAC program at a black box facility is the ability of the operator to perform accurate nuclear material accountancy and measurements and the IAEA ability to perform the same, or similar, measurements as part of their verification duties. Technology advancements in both NDA and destructive assay (DA) nuclear material measurement techniques and equipment would benefit both the operator and IAEA in their ability to fulfill their respective roles at these types of facilities.

\subsubsection{Non-destructive Assay Technologies}

Measurement techniques and equipment for NDA target a range of material characteristics such as mass, volume, and radioactivity. While technology developments to support measurement of attributes such as mass and volume are important, the greatest advancements for safeguards applications will likely come from advancement in systems that exploit the radioactive properties of materials. Progress in such NDA systems will be pushed most by the development of new detection materials, which will subsequently push development of new detection and analysis systems for use by operators and the IAEA to perform NMAC.

Efforts have been under way for several years to develop the next generation of detection materials. One area of focus has been the development and deployment of helium-3 alternative materials for the detection of neutrons because of a shortage in available helium-3. This has resulted in the development of systems that use boron-10 and lithium-6 based neutron detectors (GAO 2011). While research has shown that for some neutron detection applications these materials can meet the requirements imposed by the performance of the preferred helium-3, each has limitations (such as export restrictions) that may prevent widespread deployment. More recently, investigation into the detection capabilities of a new scintillation material known as CLYC $\left(\mathrm{Cs}_{2} \mathrm{LiYCl}_{6}\right.$ : $\left.\mathrm{Ce}\right)$ has offered a glimpse into the potential capabilities of systems that use newly developed materials. Research has shown that CLYC has excellent neutron and gammaray discrimination, and potential gamma spectroscopic capabilities, such that a system using the material might be deployed for the detection and analysis of materials emitting both neutrons and gamma rays (Glodo et al. 2007, D'Olympia et al. 2013). Any reduction in the number of detectors that the IAEA must place in a black box area, without reducing effectiveness or largely decreasing efficiency over current measures, will serve to benefit the IAEA safeguards system. CLYC may not ultimately have such capabilities; more work must be completed to fully understand the material before any deployable system is available to an operator or the IAEA. Nonetheless, such advancements in detection systems will only be possible if the development of new detection materials continues to be investigated. 


\subsubsection{Destructive Assay Technologies}

Technology development to support DA systems for NMAC needs to focus on advancements in the design of current systems used to perform DA. Facility operators perform DA measurements to ensure the quality of their process or material with high accuracy. The IAEA commonly collects and analyzes DA samples to verify operator declarations and the performance of deployed IAEA NDA systems. The role of stationary, permanent laboratories within the IAEA safeguards systems will never be replaced. These facilities offer a tightly controlled environment that the IAEA relies upon to perform traceable, defendable ${ }^{1}$ measurement results. However, these facilities also limit the extent to which DA measurements can be used by the IAEA. The annual quantity of DA samples that can be collected by inspectors and subsequently analyzed is based upon the capacity of the IAEA Safeguards Analytical Laboratory (SAL) and an approved network of analytical laboratories (NWAL) available to the IAEA (2013). Any delays from, for example, shipping of samples or temporary reduction in operational capacity (e.g., maintenance issues), affects the ability of the IAEA to meet timeliness goals for the detection of diversion or misuse. This drives the need for the IAEA to have at its disposal a system, or package of technologies, that is capable of performing DA measurements more timely and efficiently, particularly on-site at facilities undergoing inspection.

With respect to black box areas, an additional catalyst for advancements in DA technologies can be found in facilities where the IAEA must rely upon remotely operated sampling systems to collect DA samples. At the Rokkasho Reprocessing Plant (RRP) in Japan, the large number of samples collected from black boxes with radiation safety constraints necessitated creation of an on-site laboratory (OSL) capable of analyzing the samples in order to meet timeliness requirements. While the laboratory at RRP represents a unique solution for the analysis of DA samples, it demonstrates the real-world need for systems capable of performing quick, accurate DA analysis in-field by inspectors.

Across the SAL, NWAL, and OSL at RRP, the DA technique with widest application is mass spectrometry (MS), particularly the techniques of inductively coupled plasma (ICP-MS) and thermal ionization (TIMS) mass spectrometry (IAEA 2011, Ludwig et al. 2010). These systems are used to determine the elemental and isotopic composition of uranium and plutonium materials, respectively (IAEA 2011). With each technique, before a sample can be analyzed for uranium or plutonium content, each sample must be processed to remove contaminants to create a homogenous, or pure, sample that only contains the element (e.g., uranium) of interest and a known tracer element. Sample preparation for such techniques requires large amounts of time (several weeks) that must be considered when using DA as part of a safeguards approach for a black box facility. This limitation is being addressed with the development of new techniques such as electrospray ionization mass spectroscopy (ESI-MS). ESI-MS requires minimal sample preparation and in particular does not require isolation of the element of interest or introduction of a known tracer prior to analysis. This reduces the time from sample collection to production of results to hours rather than several weeks. This does come with increased uncertainty in the measurement result (1 to 5 percent with ESI-MS, instead of less than 1 percent with TIMS) but the

\footnotetext{
${ }^{1}$ All IAEA measurement procedures and results, whether DA or NDA based, are designed and approved so that the results are defensible to the IAEA Board of Governors, United Nations (UN) General Assembly, and UN Security Council.
} 
availability of such a system may allow for modified safeguards approaches that use ESI-MS as an on-site prescreen to reduce the number of samples shipped to the SAL/NWAL to only those of greatest concern. ${ }^{2}$

While improvement upon current technologies is necessary, future development should also focus on the investigation of new methods for performing DA. One such system currently being developed for near-term deployment is the laser ablation, absorbance ratio spectroscopy destructive assay (LAARS-DA) system. LAARS is a laser-based spectroscopy technique that takes advantage of the difference in the atomic absorption wavelengths of ${ }^{235} \mathrm{U}$ and ${ }^{238} \mathrm{U}$ to determine their abundance. LAARS-DA is being developed for deployment at GCEPs to perform DA on collected samples of $\mathrm{UF}_{6}$ gas from cylinders and process lines. The system has two components: the sampler assembly, and the LAARS instrument that is carried by an inspector. In application, it is expected that an inspector would expose a "coupon" of material to gaseous $\mathrm{UF}_{6}$ in a cylinder or process line and then in a sealed environment transfer the coupon to the LAARS instrument for analysis (Anheier et al. 2012). While LAARS-DA represents advancement in DA technology, it is currently only applicable to facilities that handle and process $\mathrm{UF}_{6}$. The development of such field-deployable systems that can analyze more heterogeneous material is necessary as the number of facilities processing material that requires DA measurements increases.

\subsection{Enhanced Containment and Surveillance}

The two scenarios created by black box facilities that will push the improvement in C/S technology are the application of $\mathrm{C} / \mathrm{S}$ measures within the black box area and the application at the exterior boundary of the black box area.

Within black box areas created by information protection requirements, limited inspector access may be granted. In this case, the IAEA may be permitted to apply sealing systems, or surveillance equipment that monitors parts of the process area. This has been demonstrated in cascade halls of GCEPs with the development of managed access negotiated with the operator and State and application of C/S measures in nonsensitive areas in the hall (e.g., feed and withdrawal stations are placed under surveillance). However, verification of the absence of diversion, and particularly misuse, in sensitive areas of the process is still of concern. This can be addressed with advanced sealing systems that can remotely transmit status, which can be used to indicate undeclared configuration or process design changes. Such systems exist today, one example is the electronic optical sealing system (EOSS). EOSS has been designed to operate remotely for long periods, EOSS has high reliability and tamper indication only requiring periodic inspector access, once the systems is installed by the operator (IAEA 2011). The continued development of seals, like EOSS, that incorporate the capability of monitoring position (via accelerometers, global positioning system [GPS], etc.) would allow the IAEA to remotely identify attempts to reconfigure process configurations. These seals could be placed in series along the process or attached to a black box component (whose movement would significantly degrade the effectiveness of the safeguards approach) without revealing potentially sensitive information regarding component or process design, unlike optical surveillance. These types of seals are most useful in black box areas where processes or equipment are static and not designed to be reconfigurable. However, remote monitoring at

\footnotetext{
${ }^{2}$ McDonald IV, L.W., J. A. Campbell, T. Vercouter, S.B. Clark, "Comparison between Solution and Apparent Gas Phase Speciation for Uranyl Complexed to TBP and DBP using Electrospray Ionization Mass - Mass Spectrometry," invited paper for Analytical Chemistry, not submitted at the time of this report's publication.
} 
such a sensitive facility could be problematic for a State and any use of remote monitoring would be subject to negotiation between the State and IAEA.

Reconfigurable processes within black boxes where inspector access is prohibited by information protection requirements present the greater technological challenge. In this case, as well as black boxes created by radiation protection requirements, approaches relying upon the application of $\mathrm{C} / \mathrm{S}$ at the exterior boundary of the black box will play a significant role in detecting diversion or misuse. Use of $\mathrm{C} / \mathrm{S}$ measures at the boundary of black box areas would benefit most from the development of technologies that address transport of sensitive components or highly radioactive components from a black box area to another location. The transfer of such equipment would be performed using a container that protects information regarding the sensitive component or shielding that protects personnel from any radiation hazards. This packaging or shrouding presents the operator a means to divert material from the black box area. Shrouding and shielded containers also present the operator an opportunity to introduce material or components to a black box that could be used to produce or process undeclared material without detection by the IAEA.

The IAEA has some experience in addressing the issue at GCEPs because of their information protection requirements. At select GCEPs, the IAEA and operators have agreed to operational constraints regarding the ability of the operator to introduce $\mathrm{UF}_{6}$ cylinders into the cascade hall. In this instance, $\mathrm{C} / \mathrm{S}$ measures are used to identify transfers of such containers (further detail can be found in Appendix A). However, the use of ubiquitous containers to transfer sensitive components or material still presents a challenge. As such, the IAEA would benefit from the development of non-destructive technologies that would allow it to circumvent container shrouds and shielding to verify not just the integrity of containers, but also their contents.

To address verification of container integrity, the IAEA has deployed the laser mapping system for containment verification (LMCV) of shipping containers. The system works by laser scanning a container surface to create a 3D image of minute structural defects such as cracks, pits, and dents. A reference image of the container is taken against which subsequent images are compared to identify illicit attempts to access container contents by breaching the container walls (IAEA 2011). In this application, the IAEA uses a seal to ensure there is no undetected access to the container during shipping. However, this use of seals places an increased burden on the operator. If such technology is to be used within a facility, versus between facilities, for routine transfers of shrouded or shielded equipment from black box areas, the IAEA must develop a better means of verifying container integrity.

Verification of the container integrity could potentially be bypassed if the IAEA had a means to confidently verify container contents. A similar issue arises in verification of arms control monitoring arrangements where weapons design information cannot be disclosed during transfers or dismantlement. In this area, research is being performed to investigate the application of x-ray radiography or tomography instruments to image the contents of containers (Robinson et al. 2012). These imaging techniques offer a great level of detail to users, requiring the use of information barriers to protect sensitive information. Additionally, their current size and costs would prohibit their use as part of a safeguards approach for common black box areas. Thus, for transfers from black box areas the IAEA is in need of better technology solutions to efficiently safeguard against diversion or misuse paths that take advantage of shrouded or shielded containers. Any such development would need to involve the State, operator, and IAEA to ensure that the IAEA's needs are met without violating black box constraints. This not only 
includes collaboration regarding facility design, but also container design and operational constraints as to the allowance of certain containers into the black box area.

\subsection{Design Information Process}

Current technologies available to the IAEA for DIE/DIV are restricted the least by black boxes created from radiation protection requirements. The IAEA has some experience in developing approaches under these constraints. In such facilities, whether they contain static or reconfigurable processes, the IAEA performs DIV activities prior to the creation of the radiation hazard within the black box area. Access ports to the black box area are then maintained under C/S measures so subsequent DIE/DIV are not required, given no changes in design are reported nor undeclared access suspected. Additionally, the IAEA can install additional C/S measures (e.g., surveillance) within the black box to maintain its conclusion that the facility was built as declared. To assist the inspector in verifying complex processes in these black boxes the IAEA has available the 3D Laser Range Finder (3DLR). The 3DLR is a mobile instrument that uses a laser to measure distances of structural objects within a facility. In its DIV role, the 3DLR is used to record a reference layout of a facility against which later scans can be compared (IAEA 2011). This technology, complemented by use of C/S, greatly enhances the ability of the inspector to verify the design of black box areas, prior to the creation of radiation hazards, or black boxes where operator needs prevent sealing of access ports.

The greater technological challenge is presented by black boxes created from information protection requirements that restrict the amount of design information reported to the IAEA. The IAEA has experience in performing design information verification in facilities where sensitive components warrant the creation of a black box. At GCEPs, inspector ability to view the centrifuges is restricted using agreed upon shrouding and managed access (discussed in Appendix A) to protect centrifuge design. However, in this instance, process piping outside of the sensitive components remains accessible to the inspector for verifying process design. When the separation of sensitive and nonsensitive components is not possible for a process design, the IAEA will need tools capable of performing DIV in a remote and unattended manner. To meet this need, it will be necessary to continue development of technologies like 3DLR that can be used to periodically scan a facility for changes. Supporting software would need to be developed that can automatically perform on-board change detection analysis to prevent disclosure of sensitive information to the IAEA. It is likely that an information barrier that provides the IAEA only a qualitative "true" or "false" as to the absence of design changes will also need to be used. Development will have to be performed in cooperation with an SSAC as IAEA responsibilities to perform maintenance may have to be carried out by an SSAC, or such DIV tools would have to be designed to be mobile, allowing the system to be carried by the inspector outside of the black box area.

DIV for processes and facilities designed to be reconfigurable within information black boxes presents additional challenges. Systems like the unattended and remote 3DLR may be applicable if a compilation of reference scans used during normal operations could be verified (potentially by the SSAC) as part of DIE and DIV activities. The system would then continue to provide assurances that misuse has not taken place as the facility design is changed as part of normal operations. Such a set of constraints upon DIV may be better addressed with the development of technologies capable of detecting undeclared penetrations from the exterior of the black box. These would be systems like ground penetrating radar that provide the IAEA a means to detect the presence of pipes concealed within structural elements. Advancements in gamma cameras, used in concert with systems like 3DLR, could also be used to exploit 
the radioactive properties of complex facilities to map nuclear material flows without revealing process data (Durst et al. 2009).

\subsection{Environmental Sampling and Analysis}

Black box constraints, particularly in instances where DIE/DIV and application of C/S measures are restricted, will require an increased dependence upon environmental sampling and analysis by the IAEA to detect facility misuse. To meet this need and maintain detection timeliness, advancements in technologies to collect and analyze environmental samples are necessary.

The IAEA relies upon an inspector's ability to physically collect environmental samples at facilities that are then shipped (by operators with samples under IAEA seal) and processed at authorized laboratories. However, in facilities where inspector access is limited or precluded by black box constraints, this ability is restricted. As discussed in Appendix A, the IAEA currently demonstrates proficiency at collection of environmental samples under limited access constraints at GCEPs. Technology to support this capability is being furthered with development of technologies such as Laser Ablation, Absorbance Ratio Spectroscopy Environmental Sampling (LAARS-ES). LAARS-ES uses the same laser spectroscopy technique to determine ${ }^{235} \mathrm{U}$ and ${ }^{238} \mathrm{U}$ abundance as the previously discussed LAARS-DA system. However, the LAARS-ES system is designed to use an unattended collection system that stores aerosol samples on a drum covered in a specialized matrix that an inspector would then remove and analyze using the LAARS instrument during an inspection (Anheier and Bushaw 2010). This type of collection and analysis can be used verify the absence of undeclared activities in a matter of minutes, on-site, versus several weeks with current methods.

Presenting a greater technological challenge to the IAEA are black box areas that entirely preclude direct inspector access because of information or radiation protection requirements. As a safeguards measure, environmental sampling cannot be easily replaced, nor quickly placed aside, because of black box constraints since environmental sampling provides a high confidence in conclusions of misuse. As such, sampling and analysis systems must be developed that can be installed prior to the introduction of material/sensitive components, or carried by an inspector. Systems installed at a facility would be required to operate in a completely unattended manner for extended periods of time with high reliability, integrating both the collection and analysis aspects of environmental sampling. The role of an inspector is unlikely to be completely eliminated as any installed equipment will require maintenance and integrity verification, so technology development should focus on systems capable of being carried by an inspector. Such development could focus on creation of autonomous mobile platforms capable of collecting swipe samples, or aerosol samples, with analysis completed outside of the black box area using techniques such as LAARS. The mobile platform would need to be designed with tamper indication enclosures, but also an ability to detect attempts to tamper with sample collection. The use of such equipment would eliminate the need for inspector access to black box areas but maintain the benefits of environmental sampling in facilities containing such areas. 


\subsection{Process Monitoring}

Indications of material diversion and facility misuse can be found through application of process monitoring systems in black box areas. The IAEA has demonstrated a capability to perform process monitoring in instances of black box areas created by both information protection and radiation protection requirements.

The IAEA has gained experience with applying process monitoring in information protection black boxes in select GCEPs as discussed in Appendix A. In these facilities, the IAEA relies upon the continuous enrichment monitor (CEMO) to verify the absence of the production of highly enriched uranium (HEU) in cascade outlet pipes. This measurement technique takes approximately $21 / 2$ hours, given data collection and software analysis needs. To protect proprietary information, this analysis only results in a qualitative "yes" or "no" as to the presence of HEU in the pipe for inspectors. The advancement of this process monitoring system has led to the development of the advanced enrichment monitor (AEM). The AEM operates much like CEMO, however AEM is installed further downstream of the cascade outlet pipes in a location where information regarding process parameters is not considered sensitive. The drawback to this approach is that the expected installation location for the AEM is after material take-off consoles, meaning there is an opportunity to remove material prior to its measurement (Ianakiev et al. 2010).

Most recently with the Rokkasho Reprocessing Plant, the IAEA has gained experience with application of process monitoring under radiation protection constraints. During the design of the facility, the IAEA worked with the State and operator to design the solution measurement and monitoring system (SMMS). The SMMS is capable of remotely verifying inventories and transfers of highly radioactive materials among MBAs using a complex system of pressure and temperature sensors installed on key process tanks throughout the facility (IAEA 2011). Using evaluation software, the SMMS is capable of distinguishing between tank filling, holding, mixing, and transferring activities and determining if the facility is operating as declared. The system works in concert with the automatic sampling and authentication system (ASAS) that collects samples of process material and transfers the samples to an on-site laboratory for analysis using destructive and non-destructive techniques (Johnson et al. 2001).

Development of technologies to support process monitoring under black box constraints should continue to address the unique, facility specific challenges presented by enrichment and reprocessing facilities. At GCEPs, the IAEA currently has the ability to verify on-line the absence of the production of HEU with systems like CEMO. However, the IAEA's ability to verify if a facility is being used to produce undeclared material within allowable purities is spread across application of C/S measures, limited frequency unannounced access (LFUA), and NMAC. Technologies that monitor process control data throughout the facility (e.g., real-time monitoring of load cell data, monitoring of flow rates, etc.) to create a system analogous to SMMS would better assist the IAEA in completing its verification objective. In reprocessing facilities, SMMS provides the IAEA the ability to remotely and autonomously verify that no undeclared production has occurred. However, the IAEA must rely upon sampling systems such as ASAS to verify that material produced is as declared. The IAEA would gain benefit from the development of systems that allow for the online, non-destructive analysis and verification of materials. The need for off-site sample analysis or on-site laboratories with such a system would be reduced, or eliminated, increasing efficiency and improving the timeliness of information available to inspectors. 


\subsection{Conclusions}

The determination of whether a black box process is safeguardable is very dependent upon the details of the process type, design, and layout; the specific limitations on inspector access; and the design information that can be provided to the IAEA. Therefore, this analysis has focused on deriving necessary conditions for safeguardability. That is, the black box process will be sufficiently safeguardable if the facility, black box process, and, limitations on IAEA access to equipment, areas, and information meet the following requirements:

- The black box process is located within an area of the facility that is surrounded by a physical containment barrier and has been defined as a MBA. The flow key measurement points for the black box process MBA are located outside of the containment physical barrier and are accessible for IAEA inspection.

- The NMAC system has sufficient accuracy to detect the loss or diversion of the "test statistic" from the black box process MBA in a timely fashion.

- The design and layout of the black box process or area permit inspector verification of the measured values of the material balance components for the black box process MBA, with the exception of the quantity of nuclear material in inventory identified as unverifiable in the design information submittal.

- The design and layout of the black box process or area permit the installation and operation of $\mathrm{C} / \mathrm{S}$ that provide assurance that all physical transfers and all transfers of nuclear material are reflected in the NMAC system, including measures to ensure that transfers of sensitive or radioactive equipment into and out of the black box process MBA cannot be used to conceal transfers of undeclared nuclear material.

- The design and layout of the black box process or area permit design verification by inspector examination or other means to ensure that no undeclared penetrations have been made to the physical barrier surrounding the black box area.

- The design and layout of the black box process or area permit inspector design verifications to ensure that the as-built facility has not changed in ways that degrade the effectiveness of the containment or surveillance measures relied upon for detecting diversion and misuse in the established safeguards approach.

- The design information provided by the State is sufficient for the IAEA to identify misuse paths (scenarios) and indicators, for all planned process configurations and to develop a safeguards approach that closes the misuse paths, through design features or safeguards measures, or detects their use and that can reliably identify undeclared process reconfigurations preclude or detect initiation of undeclared activities, and monitor misuse indicators.

Although these requirements are necessary for safeguardability, additional measures may be required to establish safeguardability in specific cases. For example, IAEA measures typically relied upon to detect diversion and misuse will be of little use at facilities enclosed by a black box that entirely prohibits inspector access and restricts all access to design information. In this instance, the powers granted to the IAEA in a State with an AP in force will be essential to the ability of the IAEA to verify that no diversion has occurred and that no undeclared material or activities have been pursued by the State. 
In practice it is likely that, should a State pursue the construction of a facility entirely enclosed by a black box, the facility designer, operator, and State would have to work with the IAEA to reduce the size of the black box. However, as much of the facility information may be considered sensitive by the State, the IAEA could only play a limited role. Thus, the development of safeguards design guidance and tools for determining safeguardability for use by facility designers, operators, and States, independent of engagement with the IAEA, will be crucial to reduce the need for black boxes that encompass entire facilities. With these types of tools, the safeguardability evaluation of black box processes can be initiated early in the design process such that design or process modifications can be completed to ensure that the as built facility is safeguardable.

While the compensatory measures proposed address the ability of the IAEA to perform verification activities at black box facilities, ultimately there may be instances where the IAEA must rely upon an SSAC or regional system for accounting and control to perform the verification action. The IAEA has established a precedent for such alternative inspection procedures with light-water reactors (LWRs) without mixed-oxide (MOX) fuel ${ }^{1}$ and low enriched uranium (LEU), depleted, and natural uranium conversion and fuel fabrication plants ${ }^{2}$. Such a cooperation arrangement could be developed between the IAEA and SSAC that is responsible for the black box facility.

Some of the challenges discussed will be best addressed by operational constraints or modification of safeguards approaches at facilities with black box areas. However, challenges that necessitate advancement in available technology to support the application of safeguards measures in these facilities remain. Verification capabilities of the IAEA at black box facilities can best be enhanced with the development of

- advanced detection materials that will push advancement in the NDA and DA systems available to perform nuclear material measurement in support of NMAC

- $\mathrm{C} / \mathrm{S}$ measures designed for use within black boxes where the IAEA has limited access and for use at the exterior of the black box boundary to verify container integrity and contents

- systems capable of performing unattended, remote design information verification within black box areas and technologies capable of detecting undeclared, or hidden, penetrations from outside the black box

- advanced systems capable of performing environmental sampling and analysis on-site

- real-time, or near real-time, process monitoring systems capable of operating in an unattended manner and remotely or in sensitive process areas.

\footnotetext{
${ }^{1}$ Safeguards Manual, SMC 14, Annex 10, Alternative Procedures for Interim Inspections for Timely Detection at LWRs Without MOX Fuel

${ }^{2}$ Safeguards Manual, SMC 14, Annex 11, Alternative Procedures for DNLEU Conversion And Fuel Fabrication Plants
} 


\subsection{References}

Anheier N and B Bushaw. 2010. "Unattended Environmental Sampling and Laser-based Enrichment Assay for Detection of Undeclared HEU Production in Enrichment Plants", Pacific Northwest International Conference On Global Nuclear Security - the Decade Ahead, Portland Oregon, April 11-16, 2010. Available at http://www.inmm.org/PNNL_Conference_Papers.htm.

Anheier, N, BD Cannon, HA Qiao, JC Carter, BK McNamara, MJ O’Hara, JR Phillips, and MM Curtis. 2012. "Onsite Gaseous Centrifuge Enrichment Plant UF6 Cylinder Destructive Assay." In 53rd Annual Meeting of the Institute of Nuclear Materials Management 2012, p. 764. Curran Associates, Inc., Red Hook, New York.

Bari RA, J Hockert, EF Wonder, III, SJ Johnson, R Wigeland, and MD Zentner. 2012. Overview of the Facility Safeguardability Analysis (FSA) Process. PNNL-21698, Pacific Northwest National Laboratory, Richland, Washington.

Boyer B, JM Whitaker, JL White-Horton, KR Durbin, "Next Generation Safeguards Initiative: Overview and Policy Context of UF6 Cylinder Tracking Program," In 53rd Annual Meeting of the Institute of Nuclear Materials Management 2012, p.3250. Curran Associates, Inc., Red Hook, New York.

D’Olympia N, P Chowdhury, CJ Lister, J Glodo, R Hawrami, K Shah, U Shirwadkar. 2013 "Pulse-shape analysis of CLYC for thermal neutrons, fast neutrons, and gamma-rays." Nuclear Instruments and Methods in Physics Research A 714 :121-127.

Doyle JE (ed.). 2008. Nuclear Safeguards, Security, and Nonproliferation: Achieving Security with Technology and Policy, Butterworth-Heinemann, Burlington, Massachusetts.

Durst PC, R Metcalf, R Bean, T Bjornard, B Boyer, M Burks, A Dougen, B Smith, M Watkins, M Ehinger, D Few, D Hanks, G Lancaster, K Michel, L Mihailescu, J Morgan, and K Tolk. 2009. Report on the Workshop on Nuclear Facility Design Information Verification for Safeguards.

INL/EXT-09-15744, Idaho National Laboratory, Idaho Falls, Idaho..

GAO - United States Government Accountability Office. 2011. Technology Assessment: Neutron detectors, Alternatives to using helium-3. GAO-11-753. Available at http://www.gao.gov/assets/590/585514.pdf.

Glodo J, W Brys, G Entine, WH Higgins, EVD van Loef, MR Squillante, and KS Shah 2007. "Cs2LiYCl6:Ce Neutron Gamma Detection System," In 2007 IEEE Nuclear Science Symposium Conference Record. p 959. IEEE, Piscataway, New Jersey,

Guizzo, E. 2006. "How Brazil Spun the Atom.” IEEE Spectrum, , March 2006. Accessed August 19, 2013 at http://spectrum.iee.org/energy/nuclear/how-brazil-spun-the-atom/0.

IAEA - International Atomic Energy Agency. 1968. The Agency's Safeguards System (1965, as Provisionally Extended in 1966 and 1968). INFCIRC/66/Rev.2, International Atomic Energy Agency, Vienna. Available at http://www.iaea.org/Publications/Documents/Infcircs/Others/infcirc66r2.pdf. 
IAEA - International Atomic Energy Agency. 1972. The Structure and Content of Agreements between the Agency and States Required in Connection with the Treaty on the Non-Proliferation of Nuclear Weapons. INFCIRC/153 (corrected), International Atomic Energy Agency, Vienna. Available at http://www.iaea.org/Publications/Documents/Infcircs/Others/infcirc153.pdf .

IAEA - International Atomic Energy Agency. 1982. IAEA Safeguards Technical Manual, Part F Volume 3. IAEA-TECDOC-261, International Atomic Energy Agency, Vienna, 1982. Available at http://www-pub.iaea.org/MTCD/publications/PDF/te_261_web.pdf.

IAEA - International Atomic Energy Agency. 1997. Model Protocol Additional to the Agreement( $s$ ) between State( $s$ ) and the International Atomic Energy Agency for the Application of Safeguards. INFCIRC/540 (corrected), International Atomic Energy Agency, Vienna. Available at http://www.iaea.org/Publications/Documents/Infcircs/1997/infcirc540c.pdf.

IAEA - International Atomic Energy Agency. 2002. Safeguards Glossary, 2001 Edition. International Nuclear Verification Series No. 3, International Atomic Energy Agency, Vienna. Available at http://www-pub.iaea.org/MTCD/publications/PDF/nvs-3-cd/PDF/NVS3 scr.pdf.

IAEA - International Atomic Energy Agency. 2008. Nuclear Material Accounting Handbook. IAEA Services Series 15, International Atomic Energy Agency, Vienna. Available at http://wwwpub.iaea.org/MTCD/publications/PDF/svs_015_web.pdf

IAEA - International Atomic Energy Agency. 2010. International Target Values 2010 for Measurement Uncertainties in Safeguarding Nuclear Materials. STR-368, International Atomic Energy Agency, Vienna, Available at http://www.iaea.org/OurWork/SG/documents/International_Target_Values_2010.pdf.

IAEA - International Atomic Energy Agency. 2011. IAEA Safeguards Techniques and Equipment: 2011 Edition, International Nuclear Verification Series No. 1 (Rev.2), International Atomic Energy Agency, Vienna. Available at http://www-pub.iaea.org/MTCD/Publications/PDF/nvs1_web.pdf.

IAEA - International Atomic Energy Agency. 2013. Safeguards Statement for 2011, International Atomic Energy Agency, Vienna, Austria. Accessed August 20, 2013 at http://www.iaea.org/safeguards/documents/es2011.pdf.

Ianakiev K, B Boyer, A Favalli, JM Goda, T Hill, C Keller, M Lombardi, M Paffett, DW MacArthur, C McCluskey, CE Moss, R Parker, MK Smith, MT Swinhoe, R Gunnink, and S Joe. 2010. "Paper \#182 Advanced Technology for Enrichment Monitoring in UF6 Gas Centrifuge Enrichment Plants." LA-UR10-06263, Los Alamos National Laboratory, Albuquerque, New Mexico.

Ianakiev KD, M Lombardi, DW MacArthur, RF Parker, MK Smith, C Keller, PJ Friend, and A Dunford. 2012. "Field Trial of LANL On-Line Advanced Enrichment Monitor for UF6 GCEP." In the 53rd Annual Meeting of the Institute of Nuclear Materials Management. p.773. Curran Associates, Inc., Red Hook, New York.

Johnson SJ, R Abedin-Zadeh, C Pearsall, K Hiruta, C Creusot, M Ehinger, E Kuhn, B Chesnay, N Robson, H Higuchi, S Takeda, K Fujimaki, H Ai, S Uehara, H Amano, and K Hoshi. 2001.

"Development of the Safeguards Approach for the Rokkasho Reprocessing Plant."IAEA-SM-367/8/01, In 
Proceeding of the IAEA Symposium on International Safeguards: Verification and Nuclear Material Security, International Atomic Energy Agency, Vienna, Austria.

Ludwig R, G Duhamel, V Mayorov, K Nagy, K Raptis, T Hayakawa, M Midorikawa, Y Sato, S Hara, T Itoh, Y Itoh, and T Suto. 2010. "Quality Control in the OSL Rokkasho: Status after Four Years of Operation,” ESARDA Bulletin, No. 44:40-47.

Peixoto, OJM and OC Larrieu. 2009. "Safeguards at the Commercial Centrifuge Plant at Resende, Brazil." In the Proceedings of the $59^{\text {th }}$ Annual Meeting of the Institute of Nuclear Materials Management Annual Meeting 2009, Curran Associates, Red Hook, New York, p.3042.

Robinson, SM, KD Jarman, WK Pitts, A Seifert, AC Misner, ML Woodring, and MJ Myjak. 2012. "Imaging for dismantlement verification: Information management and analysis algorithms." Nuclear Instruments and Methods in Physics Research Section A: Accelerators, Spectrometers, Detectors and Associated Equipment, 662(1):81-89. 


\section{Appendix A}

\section{Information/Technology Protection Measures at Current}

GCEP 


\section{Appendix A}

\section{Information/Technology Protection Measures at Current GCEP}

The enrichment facility at Resende, Brazil is a gas centrifuge enrichment plant (GCEP) with a capacity of less than 114 metric tonnes - separative work units (MTSWU) per year. ${ }^{1}$ However, the capacity of the plant will increase to 200 MTSWU when the second stage is completed (INB 2013). The plant has a large number of centrifuges in cascades that are installed in the process area, grouped in modules, and housed in independent buildings. ${ }^{2}$ All the cascades are connected in parallel and the capacity of each cascade is declared in the design information. The facility is designed to produce less than 5 percent enriched uranium handled in $30 \mathrm{~B}$ cylinders. Both the natural uranium used as feed material and the tails of depleted uranium are handled in $48 \mathrm{Y}$ cylinders. The process facility sampling points are delineated in the design information and sampling locations and procedures permit the application of International Atomic Energy Agency (IAEA) containment and surveillance measures at these points. There is a common feed and withdrawal $(\mathrm{F} \& \mathrm{~W})$ station, where the access to process weighing system is allowed for inspection purposes. The feed cylinders are connected to standard commercial autoclaves and the product and tail cylinders are taken out through pressure and temperature measurement devices. Measures to facilitate the identification of connected cylinders at any moment in the $\mathrm{F} \& \mathrm{~W}$ station have been adopted by design. All the junctions in the main cascade headers between the cascade hall and the $\mathrm{F} \& \mathrm{~W}$ station are welded. However, the piping has been designed and installed so that the facility has some flexibility to realign portions of the cascade to optimize the process. All the cascades have a common vacuum system.

For this facility, the sensitive information to be protected relates to the design of the centrifuges. During inspections, the inspectors have full access to the $\mathrm{F} \& \mathrm{~W}$ station to observe and verify measurements of cylinder uranium element and isotope weight. The inspectors have access to the general vacuum station and to the building (confinement). Inspectors also have physical access to the cascade halls but not complete visual access. The facility has been designed to permit visual access to the cascade piping and the main header to permit inspector verification that the configuration has not been changed. The upper piping going to each centrifuge is visible to inspectors; however, the centrifuges are concealed behind panels to protect sensitive design information. In addition, the inspector visual access is sufficient to verify that clandestine piping or unidentified support equipment has not been installed in the portions of the process area outside of the panels that conceal the centrifuges.

The design of this enrichment facility corresponds to one of the more transparent types of conceivable black box facilities. This limited the inspectors' ability to directly observe some aspects of the configuration of the centrifuge cascade.

\footnotetext{
${ }^{1}$ The separative work unit (SWU) is a measure of the work expended during an enrichment process that is a function of the concentrations of the feedstock, the enriched output, and the depleted tailings; and is expressed in units which are so calculated as to be proportional to the total input (energy/machine operation time) and to the mass processed.

${ }^{2}$ Information in the remainder of this introductory material is taken from Peixoto and Osvaldo 2009 and one author's (Helly Diaz Marcano) personal knowledge as an IAEA inspector at the Resende GCEP.
} 


\section{A.1 IAEA Safeguards Approach for Facilities with Black Box Areas or Processes}

The safeguards approach for the Resende facility agreed to by the IAEA and the State includes ${ }^{1}$ containment and surveillance, inspection regime, physical inventory verifications, environmental sampling, and verification of $\mathrm{U} /{ }^{235} \mathrm{U}$ mass balance and SWU capacity usage.

\section{A.1.1 Containment and Surveillance}

The following containment and surveillance $(\mathrm{C} / \mathrm{S})$ measures are employed:

- $\mathrm{C} / \mathrm{S}$ at the $\mathrm{UF}_{6}$ feed and withdrawal $(\mathrm{F} \& \mathrm{~W})$ station in order to maintain the continuity of knowledge on all connected feed and withdrawal cylinders

- $\mathrm{C} / \mathrm{S}$ measures on strategic points inside the vacuum system ${ }^{2}$

- special coverage by $\mathrm{C} / \mathrm{S}$ measures of any potential feed point in the feed line

- continuity of knowledge on the disconnected cylinders using variable coding seal system (VACOSS) seals linked with the surveillance system.

\section{A.1.2 Inspection Regime}

The inspection regime includes all of the following:

- one annual physical inventory verification (PIV)

- 11 monthly interim inspections (mainly for flow verification)

- verification of nuclear material inventory of the feed, product, and tail cylinders, including receipts and shipments. The operator had to hold the feed cylinders (before being fed into the process) and the tails and products cylinders (before being shipped off-site) for verification

- auditing of facility records and State reports routinely submitted to the IAEA (i.e., Inventory Change Report, Physical Inventory Listing, and Material Balance Report)

- material balance evaluation

- application of agency seals to $\mathrm{UF}_{6}$ cylinders.

Inspectors also review surveillance data during both interim and unannounced inspections. During interim inspections the review covers the entire period since the last interim inspection. During unannounced inspections, the review is limited to the period since the event that triggered the inspection and the review of camera data is limited to cameras covering critical points.

\footnotetext{
${ }^{1}$ Information in Section 1.0 of Appendix A is taken from Peixoto and Larrieu 2009 and one author's (Helly Diaz Marcano) personal knowledge as an IAEA inspector at the Resende GCEP.

${ }^{2}$ The available design information about the Resende GCEP is quite limited. Peixoto and Larrieu (2009) imply that there are also $\mathrm{C} / \mathrm{S}$ measures on sampling points in the cascade hall and in feed lines where undeclared feed or withdrawal activities are feasible. The author with personal knowledge does not recall any $\mathrm{C} / \mathrm{S}$ measures inside the cascade hall at the time of his inspections (up to July 2011). Such measures would be appropriate for this type of black box process; but the surveillance field of view might need to be limited to protect sensitive information.
} 
Inspectors also visit the process areas during routine, interim, and unannounced inspections to verify the design information and to provide assurance that the facility has not been reconfigured to permit misuse. Inspector access to the process areas is governed by agreed-upon procedures to ensure that sensitive information is protected. To verify the configuration of piping in the areas concealed by panels, to which inspector visual access is denied, the operator is asked to take pictures of piping on randomly selected centrifuges. ${ }^{1}$ These pictures are compared to pictures taken when the cascade first started. The pictures are left at the facility under IAEA and Brazilian-Argentine Agency for Accounting and Control of Nuclear Materials (ABACC) seals. A review of all surveillance camera images within a given period is performed to confirm the absence of undeclared activities or nuclear material. Randomly selected cascade panels and points are used for ' go - no go' gamma and transmissivity measurements. This process uses a gamma detector system set up to detect a gamma source situated on the opposite side of the cascade, at the exact position of the detector. The process is then repeated without the source to account for background. The background radiation data measured are expected to be equal to or below the baseline data collected when the cascade was first started because an increase in the gamma radiation level being monitored could be an indication of the presence of higher uranium enrichment levels in the cascade hall.

\section{A.2 Physical Inventory Verifications}

All $\mathrm{UF}_{6}$ cylinders in the storage yard are inventoried. In addition, $\mathrm{UF}_{6}$ cylinders connected to the cascade and to the process vessel (F\&W stations) are inventoried. Flow is verified during both PIVs and interim inspections. The flow includes $\mathrm{UF}_{6}$ feed, product, and tails cylinders, as well as minor waste streams, such as trap material.

The inspector weighs a random number of non-empty $\mathrm{UF}_{6}$ cylinders under each stratum (e.g., $30 \mathrm{~B}$ and $48 \mathrm{Y}$ ), using the IAEA load-cell based weighing system. The operator's scales are also authenticated using IAEA calibrated weights. A random number of $\mathrm{UF}_{6}$ cylinders are also selected for gross and partial non-destructive assay (NDA) measurements, as well as destructive assay (DA) measurements to estimate bias.

\section{A.3 Environmental Sampling}

Environmental swipe sampling is carried out on random basis during the year. Swipe samples are collected following agreed upon procedures on those strategic areas referenced in the Facility Attachment. Strategic areas located inside the cascade hall are sampled during unannounced inspections and areas located outside the cascade hall are sampled during interim inspections. During the PIV, samples can be collected at any area identified in the Facility Attachment.

\section{A.4 Verification of $\mathrm{U} /{ }^{235} \mathrm{U}$ Mass Balance and SWU Capacity Usage}

During the PIV and randomly selected inspections during the year, the inspector takes simultaneous DA samples from the feed, product, and tails line, and collects information from the load cells at the $\mathrm{UF}_{6}$

\footnotetext{
${ }^{1}$ It should be noted that the inspector does not see the actual picture taking operation as this takes place behind the shielded area.
} 
F\&W station. This information is compared with the following information that is reported monthly to the IAEA:

- amounts of feed, product, and tails forecast for each of the next three months

- the weights of the feed, product and tails cylinders connected to the process expressed as unified uranium (element and isotope)

- forecast monthly separative work unit (SWU) to be processed for each of the next three months.

In addition, the following information is requested in advance of inspections:

- projected $\mathrm{UF}_{6}$ receipts from outside facilities

- projected shipments from the facility

- projected increase in the installed capacity

- operational and maintenance activities in the cascade area, $\mathrm{UF}_{6} \mathrm{~F} \& \mathrm{~W}$ station, and vacuum station that might have an impact on the safeguards approach

- the scheduled date for PIV.

\section{A.5 References}

IAEA - International Atomic Energy Agency. 2013. "INB -Resende Enrichment Plant.” IAEA Nuclear Fuel Cycle Information System. Accessed on August 19, 2013 at http://infcis.iaea.org/NFCIS/FacilityDetails/694.

Peixoto, OJM and OC Larrieu. 2009. "Safeguards at the Commercial Centrifuge Plant at Resende, Brazil." In the Proceedings of the $59^{\text {th }}$ Annual Meeting of the Institute of Nuclear Materials Management Annual Meeting 2009, Curran Associates, Red Hook, New York, p.3042. 


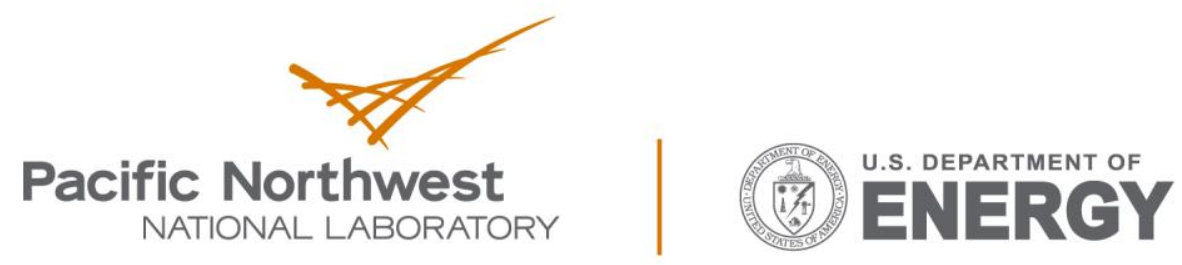

Proudly Operated by Battelle Since 1965

902 Battelle Boulevard

P.O. Box 999

Richland, WA 99352

1-888-375-PNNL (7665)

www.pnnl.gov 